\title{
Is the Chronic Kidney Disease Epidemiology Collaboration creatinine-cystatin $C$ equation useful for glomerular filtration rate estimation in the elderly?
}

\author{
This article was published in the following Dove Press journal: \\ Clinical Interventions in Aging \\ 10 October 2013 \\ Number of times this article has been viewed
}

\author{
Xun Liu' ${ }^{1,2, *}$ \\ Huijuan Ma ${ }^{1, *}$ \\ Hui Huang ${ }^{3}$ \\ Cheng Wang' \\ Hua Tang' \\ Ming $\mathrm{Li}^{\prime}$ \\ Yanni Wang' \\ Tanqi Lou' \\ 'Division of Nephrology, Department \\ of Internal Medicine, The Third \\ Affiliated Hospital of Sun Yat-sen \\ University, ${ }^{2}$ College of Biology \\ Engineering, South China University \\ of Technology, ${ }^{3}$ Department of \\ Cardiology, Sun Yat-sen Memorial \\ Hospital of Sun Yat-sen University, \\ Guangzhou, People's Republic of \\ China \\ *These authors contributed equally \\ to the paper
}

Background: We aimed to evaluate the performance of the Chronic Kidney Disease Epidemiology Collaboration (CKD-EPI) creatinine-cystatin C equation in a cohort of elderly Chinese participants.

Materials and methods: Glomerular filtration rate (GFR) was measured in 431 elderly Chinese participants by the technetium-99m diethylene-triamine-penta-acetic acid ( $\left.{ }^{99 \mathrm{~m}} \mathrm{Tc}-\mathrm{DTPA}\right)$ renal dynamic imaging method, and was calibrated equally to the dual plasma sample ${ }^{99 \mathrm{~m}}$ Tc-DTPA-GFR. Performance of the CKD-EPI creatinine-cystatin C equation was compared with the CockcroftGault equation, the re-expressed 4-variable Modification of Diet in Renal Disease (MDRD) equation, and the CKD-EPI creatinine equation.

Results: Although the bias of the CKD-EPI creatinine-cystatin C equation was greater than with the other equations (median difference, $5.7 \mathrm{~mL} /$ minute $/ 1.73 \mathrm{~m}^{2}$ versus a range from $0.4-2.5 \mathrm{~mL} /$ minute $/ 1.73 \mathrm{~m}^{2} ; P<0.001$ for all), the precision was improved with the CKD-EPI creatinine-cystatin $\mathrm{C}$ equation (interquartile range for the difference, $19.5 \mathrm{~mL} /$ minute $/ 1.73 \mathrm{~m}^{2}$ versus a range from $23.0-23.6 \mathrm{~mL} /$ minute $/ 1.73 \mathrm{~m}^{2} ; P<0.001$ for all comparisons), leading to slight improvement in accuracy (median absolute difference, $10.5 \mathrm{~mL} /$ minute $/ 1.73 \mathrm{~m}^{2}$ versus 12.2 and $11.4 \mathrm{~mL} /$ minute $/ 1.73 \mathrm{~m}^{2}$ for the Cockcroft-Gault equation and the re-expressed 4-variable MDRD equation, $P=0.04$ for both; $11.6 \mathrm{~mL} /$ minute $/ 1.73 \mathrm{~m}^{2}$ for the CKD-EPI creatinine equation, $P=0.11$ ), as the optimal scores of performance (6.0 versus a range from 1.0-2.0 for the other equations). Higher GFR category and diabetes were independent factors that negatively correlated with the accuracy of the CKD-EPI creatinine-cystatin C equation $(\beta=-0.184$ and $-0.113, P<0.001$ and $P=0.02$, respectively).

Conclusion: Compared with the creatinine-based equations, the CKD-EPI creatinine-cystatin $\mathrm{C}$ equation is more suitable for the elderly Chinese population. However, the cost-effectiveness of the CKD-EPI creatinine-cystatin $\mathrm{C}$ equation for clinical use should be considered.

Keywords: elderly, equation, glomerular filtration rate, serum creatinine, cystatin $\mathrm{C}$

\section{Introduction}

Chronic kidney disease (CKD) is common in the elderly. ${ }^{1}$ Glomerular filtration rate (GFR) is the best index of overall kidney function. ${ }^{2}$ In two previous studies, ${ }^{3,4}$ we found that creatinine-based GFR predicting equations were not suitable for elderly Chinese patients with CKD. In the present study, several improvements to study design were made. First, cystatin $\mathrm{C}$ was added as a new predicting variable, and was traceable to standard reference material for cystatin $\mathrm{C}$ measurement. Second, GFR was measured by the technetium-99m diethylene-triamine-penta-acetic acid ( $\left.{ }^{99 \mathrm{~m}} \mathrm{Tc}-\mathrm{DTPA}\right)$ renal dynamic
Correspondence: Tanqi Lou Division of Nephrology, Department of Internal Medicine, The Third Affiliated Hospital of Sun Yat-sen University, \#600,Tianhe Road, Guangzhou, 510630 People's Republic of China

Email lou.tq@163.com 
imaging method, and was calibrated equally to the dual plasma sample ${ }^{99 \mathrm{~m}}$ Tc-DTPA-GFR. Third, sample size was increased. We aimed to evaluate the performance of the new CKD Epidemiology Collaboration (CKD-EPI) creatinine-cystatin C equation $^{5}$ in a cohort of elderly Chinese participants, compared with the creatinine-based equations.

\section{Materials and methods}

\section{Participants}

Participants aged 60 years or older in the Third Affiliated Hospital of Sun Yat-sen University, People's Republic of China were enrolled between January 2010 and December 2012. Exclusion criteria included: 1) acute kidney function deterioration, edema, skeletal muscle atrophy, pleural effusion or ascites, malnutrition, amputation, heart failure, and ketoacidosis, or 2) on cimetidine or trimethoprim, or 3) being treated with dialysis at the time of the study. Study approval was obtained from the institutional review board at the Third Affiliated Hospital of Sun Yat-sen University. Informed consent of subjects was obtained prior to the beginning of the study.

\section{Laboratory methods}

GFR was measured by the ${ }^{99 \mathrm{~m}}$ Tc-DTPA renal dynamic imaging method, ${ }^{6,7}$ as described previously. ${ }^{8}$ According to the method developed by Ma et al, ${ }^{9}$ we determined the minimum sample size to be 36 (95\% confidence interval and 80\% power), using Open Epi Version 2 (http://www.openepi. $\underline{\mathrm{com}})^{10}$ to compare means (in order to ensure that our measured GFR [mGFR] values were calibrated equally to the dual plasma sample ${ }^{99 m}$ Tc-DTPA-GFR). Calculation was based on the findings in a previous Chinese study. ${ }^{11}$ We randomly selected 36 cases (GFR measured by the DTPA renal dynamic imaging method, range $15.6-106.3 \mathrm{~mL} /$ minute $/ 1.73 \mathrm{~m}^{2}$ ) and performed the dual plasma samples method ${ }^{99 \mathrm{~m}}$ Tc-DTPA clearance simultaneously with the renal dynamic imaging. After image acquisition, blood samples were taken 2 and 4 hours after injection from the opposite forearm. The plasma was separated, and radioactivity was counted in a multi-function well counter (ZD-6000 multi-function instrument; Zhida Technology Company, Xian, People's Republic of China). ${ }^{12}$ The ${ }^{99 m}$ Tc-DTPA renal dynamic imaging GFR measured in our study can be calibrated to dual plasma samples ${ }^{99 \mathrm{~m}}$ Tc-DTPA clearance GFR using a linear regression equation:

Dual plasma sample ${ }^{99 \mathrm{~m}}$ Tc-DTPA-GFR (mL/minute $\left./ 1.73 \mathrm{~m}^{2}\right)$ $=-2.586+1.106 \times{ }^{99 m}$ Tc-DTPA renal dynamic imaging-GFR (mL/minute/1.73 $\left.\mathrm{m}^{2}\right)$ $\left(R^{2}=0.872, P<0.001\right)$
Serum creatinine level was measured by the enzymatic method on a Hitachi 7180 AutoAnalyzer (Hitachi Ltd, Tokyo, Japan; reagents from Roche Diagnostics, Mannheim, Germany), and recalibrated to isotope dilution mass spectrometry. Serum cystatin C assays were traceable to the certified reference materials (ERM-DA471). Performance of the CKD-EPI creatinine-cystatin $\mathrm{C}$ equation was compared with the Cockcroft-Gault equation, ${ }^{13}$ the reexpressed 4-variable Modification of Diet in Renal Disease (MDRD) equation, ${ }^{14}$ and the CKD-EPI creatinine equation ${ }^{15}$ (Table 1).

\section{Statistical analyses}

Bias was defined as the median of the difference between the mGFR and estimated GFR, and precision was measured

Table I GFR predicting equations

\begin{tabular}{|c|c|c|c|}
\hline $\begin{array}{l}\text { Basis of } \\
\text { equation } \\
\text { and sex }\end{array}$ & $\begin{array}{l}\text { Serum } \\
\text { creatinine }\end{array}$ & CYC & Equation for estimating GFR \\
\hline \multicolumn{4}{|c|}{ Cockcroft-Gault equation $^{13}$} \\
\hline & & & $(140-$ Age $) \times$ Weight $\div$ SC $\div 72$ \\
\hline & & & $\times[0.85$ if female $] \times 1.73 \div$ BSA \\
\hline \multicolumn{4}{|c|}{ Re-expressed 4-variable MDRD equation ${ }^{14}$} \\
\hline & & & $175 \times \mathrm{SC}^{-1.154} \times \mathrm{Age}^{-0.203}$ \\
\hline & & & $\times[0.742$ if female $] \times[1.212$ if Black $]$ \\
\hline \multicolumn{4}{|c|}{ CKD-EPI creatinine equation 15} \\
\hline Female & $\leq 0.7$ & & $\begin{array}{l}144 \times(S C \div 0.7)^{-0.329} \times 0.993^{\mathrm{Age}} \\
{[\times 1.159 \text { if Black }]}\end{array}$ \\
\hline Female & $>0.7$ & & $\begin{array}{l}144 \times(S C \div 0.7)^{-1.209} \times 0.993^{\mathrm{Age}} \\
{[\times 1.159 \text { if Black }]}\end{array}$ \\
\hline Male & $\leq 0.9$ & & $\begin{array}{l}14 \mathrm{I} \times(\mathrm{SC} \div 0.9)^{-0.411} \times 0.993^{\mathrm{Age}} \\
{[\times 1.159 \text { if Black }]}\end{array}$ \\
\hline Male & $>0.9$ & & $\begin{array}{l}14 \mathrm{I} \times(\mathrm{SC} \div 0.9)^{-1.209} \times 0.993^{\mathrm{Age}} \\
{[\times 1.159 \text { if Black }]}\end{array}$ \\
\hline \multicolumn{4}{|c|}{ CKD-EPI creatinine-cystatin C equation ${ }^{5}$} \\
\hline \multirow[t]{2}{*}{ Female } & $\leq 0.7$ & $\leq 0.8$ & $\begin{array}{l}130 \times(\mathrm{SC} \div 0.7)^{-0.248} \times(\mathrm{CYC} \div 0.8)^{-0.375} \\
\times(0.995)^{\mathrm{Age}} \times[1.08 \text { if Black }]\end{array}$ \\
\hline & & $>0.8$ & $\begin{array}{l}130 \times(\mathrm{SC} \div 0.7)^{-0.248} \times(\mathrm{CYC} \div 0.8)^{-0.711} \\
\times(0.995)^{\mathrm{Age}} \times[1.08 \text { if Black }]\end{array}$ \\
\hline \multirow[t]{2}{*}{ Female } & $>0.7$ & $\leq 0.8$ & $\begin{array}{l}130 \times(\mathrm{SC} \div 0.7)^{-0.601} \times(\mathrm{CYC} \div 0.8)^{-0.375} \\
\times(0.995)^{\mathrm{Age}} \times[1.08 \text { if Black }]\end{array}$ \\
\hline & & $>0.8$ & $\begin{array}{l}130 \times(\mathrm{SC} \div 0.7)^{-0.601} \times(\mathrm{CYC} \div 0.8)^{-0.711} \\
\times(0.995)^{\mathrm{Age}} \times[1.08 \text { if Black }]\end{array}$ \\
\hline \multirow[t]{2}{*}{ Male } & $\leq 0.9$ & $\leq 0.8$ & $\begin{array}{l}135 \times(\mathrm{SC} \div 0.9)^{-0.207} \times(\mathrm{CYC} \div 0.8)^{-0.375} \\
\times(0.995)^{\mathrm{Age}} \times[1.08 \text { if Black }]\end{array}$ \\
\hline & & $>0.8$ & $\begin{array}{l}135 \times(\mathrm{SC} \div 0.9)^{-0.207} \times(\mathrm{CYC} \div 0.8)^{-0.711} \\
\times(0.995)^{\mathrm{Age}} \times[1.08 \text { if Black }]\end{array}$ \\
\hline \multirow[t]{3}{*}{ Male } & $>0.9$ & $\leq 0.8$ & $\begin{array}{l}135 \times(\mathrm{SC} \div 0.9)^{-0.601} \times(\mathrm{CYC} \div 0.8)^{-0.375} \\
\times(0.995)^{\mathrm{Age}} \times[1.08 \text { if Black }]\end{array}$ \\
\hline & & $>0.8$ & $135 \times(S C \div 0.9)^{-0.601} \times(C Y C \div 0.8)^{-0.711}$ \\
\hline & & & $\times(0.995)^{\mathrm{Age}} \times[1.08$ if Black $]$ \\
\hline
\end{tabular}

Abbreviations: BSA, body surface area; CYC, cystatin C; CKD-EPI, Chronic Kidney Disease Epidemiology Collaboration; GFR, glomerular filtration rate; MDRD, Modification of Diet in Renal Disease; SC, serum creatinine. 
by the interquartile range (IQR) for the difference. Accuracy was defined by both the median of the absolute difference and percentage of estimated GFR not deviating more than $30 \%$ from the mGFR. The Wilcoxon signed-rank test was used for difference, the bootstrap method ${ }^{16}$ for IQR, and the McNemar test for 30\% accuracy. Performances of the GFR estimating equations were assessed by three aspects, including bias, precision, and accuracy. An optimal score system $^{4}$ was developed. The equation that performed the best in each aspect in the entire cohort was scored as 1 , and in each GFR subgroup as 0.5 . The greater total scores, the better synthetic performance. All calculations and statistics were performed using SPSS software (version 11.0; IBM Corporation, Armonk, NY, USA) and Matlab software (version 2011b; The Mathworks, Boston, MA, USA).

\section{Results}

A total of 431 participants aged 60 years or older were enrolled. The mean age was $69.9 \pm 6.8$ years and the mean mGFR was $53.4 \pm 26.9 \mathrm{~mL} /$ minute $/ 1.73 \mathrm{~m}^{2}$. Detailed characteristics are listed in Table 2.

Although the bias of the CKD-EPI creatinine-cystatin C equation was greater than with the other equations (median difference, $5.7 \mathrm{~mL} /$ minute $/ 1.73 \mathrm{~m}^{2}$ versus $0.4-2.5 \mathrm{~mL} /$ minute $/ 1.73 \mathrm{~m}^{2}, P<0.001$ for all comparisons), the precision was improved with the CKD-EPI creatinine-cystatin C equation (IQR for the difference, $19.5 \mathrm{~mL} / \mathrm{minute} / 1.73 \mathrm{~m}^{2}$ versus $23.0-23.6 \mathrm{~mL} / \mathrm{minute} / 1.73 \mathrm{~m}^{2}, P<0.001$ for all comparisons), leading to slight improvement in accuracy (median absolute difference, $10.5 \mathrm{~mL} /$ minute $/ 1.73 \mathrm{~m}^{2}$ versus 12.2 and $11.4 \mathrm{~mL} /$ minute $/ 1.73 \mathrm{~m}^{2}$ for the Cockcroft-Gault

Table 2 Participants, characteristics*

\begin{tabular}{|c|c|}
\hline Subjects $(n)$ & 431 \\
\hline Age (year) & $69.9 \pm 6.8$ \\
\hline Male sex (n [\%]) & $233(54.1)$ \\
\hline Diabetes (n [\%]) & $263(61.0)$ \\
\hline Body mass index $\left(\mathrm{kg} / \mathrm{m}^{2}\right)$ & $24.2 \pm 4.3$ \\
\hline Body surface area $\left(\mathrm{m}^{2}\right)$ & $1.66 \pm 0.19$ \\
\hline Serum creatinine $(\mathrm{mg} / \mathrm{dL})$ & $2.0 \pm 1.9$ \\
\hline Serum cystatin $C$ (mg/dL) & $2.0 \pm 1.2$ \\
\hline Measured GFR (mL/minute/l.73 $\left.\mathrm{m}^{2}\right)$ & $53.4 \pm 26.9$ \\
\hline \multicolumn{2}{|l|}{ GFR categories } \\
\hline$<15\left(\mathrm{~mL} /\right.$ minute $\left./ \mathrm{l} .73 \mathrm{~m}^{2}\right)$ & $33(7.7)$ \\
\hline I5-29 (mL/minute/l.73 m²) & $59(13.7)$ \\
\hline 30-59 (mL/minute/l.73 $\left.\mathrm{m}^{2}\right)$ & $174(40.4)$ \\
\hline $60-89\left(\mathrm{~mL} /\right.$ minute $\left./ \mathrm{l} .73 \mathrm{~m}^{2}\right)$ & II 8 (27.4) \\
\hline$>90\left(\mathrm{~mL} /\right.$ minute $\left./ 1.73 \mathrm{~m}^{2}\right)$ & $47(10.9)$ \\
\hline
\end{tabular}

Note: *Plus-minus values are means \pm standard deviation. Abbreviation: GFR, glomerular filtration rate. equation and the re-expressed 4-variable MDRD equation, $P=0.04$ for both; and $11.6 \mathrm{~mL} / \mathrm{minute} / 1.73 \mathrm{~m}^{2}$ for the $\mathrm{CKD}$ EPI creatinine equation, $P=0.11$ ); $30 \%$ accuracy, $59.9 \%$ versus $55.5 \%-57.5 \%, P>0.05$ for all (Table 3 ). An optimal score system was developed to evaluate the performances between different equations (Table 4). The CKD-EPI creatinine-cystatin $\mathrm{C}$ equation achieved the optimal scores (6.0 versus a range from 1.0-2.0 for the other equations).

We used multiple regression analysis to determine the factors that affected the accuracy of the CKD-EPI creatininecystatin $\mathrm{C}$ equation, with $30 \%$ accuracy of the CKD-EPI creatinine-cystatin $\mathrm{C}$ equation as the dependent variable and GFR categories (category 1 : 1 ; category $2 ; 2$ : category $3 ; 3$ : category 4 ; 4 : category $5 ; 5)$, age ( $\leq 65$ years: $1 ;>65$ years: 2 ), sex (male: 1; female: 2), diabetes (non-diabetic: 1; diabetes: 2),

Table 3 Performance between measured GFR and estimated GFR

\begin{tabular}{|c|c|c|c|c|}
\hline \multirow[t]{2}{*}{ Variable } & \multicolumn{4}{|c|}{$\begin{array}{l}\text { Measured GFR } \\
\left(\mathrm{mL} / \text { minute/l.73 } \mathrm{m}^{2}\right)\end{array}$} \\
\hline & Overall & $<\mathbf{3 0}$ & $30-59$ & $\geq 60$ \\
\hline \multicolumn{5}{|c|}{ Bias - median difference $\left(\mathrm{mL} /\right.$ minute $\left./ \mathrm{I} .73 \mathrm{~m}^{2}\right)$} \\
\hline Cockcroft-Gault equation & $2.5^{*}$ & $1.0^{*}$ & $3.3^{*}$ & $2.6^{*}$ \\
\hline Re-expressed 4-variable & $0.4 *$ & $2.0^{*}$ & I.I* & $-4.2 *$ \\
\hline \multicolumn{5}{|l|}{ MDRD equation } \\
\hline CKD-EPI creatinine equation & $0.5^{*}$ & $2.7^{\dagger}$ & $-0.4^{*}$ & $-0.7^{*}$ \\
\hline CKD-EPI creatinine-cystatin & 5.7 & 3.1 & 6.2 & 6.8 \\
\hline \multicolumn{5}{|l|}{ C equation } \\
\hline \multicolumn{5}{|c|}{ Precision - IQR for the difference $\left(\mathrm{mL} /\right.$ minute $\left./ \mathrm{I} .73 \mathrm{~m}^{2}\right)$} \\
\hline Cockcroft-Gault equation & $23.6^{*}$ & $11.4^{*}$ & $22.9 *$ & $31.7^{*}$ \\
\hline Re-expressed 4-variable & $23.6 *$ & $12.6 *$ & $23.7^{*}$ & $30.5^{*}$ \\
\hline \multicolumn{5}{|l|}{ MDRD equation } \\
\hline CKD-EPI creatinine equation & $23.0 *$ & $11.7 *$ & $25.7^{*}$ & $28.3^{*}$ \\
\hline CKD-EPI creatinine-cystatin & 19.5 & 8.8 & 22.4 & 24.6 \\
\hline \multicolumn{5}{|l|}{ C equation } \\
\hline \multicolumn{5}{|l|}{ Accuracy } \\
\hline \multicolumn{5}{|c|}{ Median absolute difference $\left(\mathrm{mL} /\right.$ minute $\left./ \mathrm{l} .73 \mathrm{~m}^{2}\right)$} \\
\hline Cockcroft-Gault equation & $12.2^{\ddagger}$ & 5.7 & 13.2 & $16.8^{\dagger}$ \\
\hline Re-expressed 4-variable & $11.4^{\ddagger}$ & $6.4^{\ddagger}$ & 11.9 & 16.0 \\
\hline \multicolumn{5}{|l|}{ MDRD equation } \\
\hline CKD-EPI creatinine equation & 11.6 & $7.0^{\dagger}$ & 12.7 & 14.0 \\
\hline CKD-EPI creatinine-cystatin & 10.5 & 6.0 & 12.7 & 12.2 \\
\hline \multicolumn{5}{|l|}{$C$ equation } \\
\hline \multicolumn{5}{|l|}{$30 \%$ accuracy $(\%)$} \\
\hline Cockcroft-Gault equation & 57.5 & 37.0 & 52.3 & 74.5 \\
\hline Re-expressed 4-variable & 57.5 & 37.0 & 55.7 & 74.5 \\
\hline \multicolumn{5}{|l|}{ MDRD equation } \\
\hline CKD-EPI creatinine equation & 55.5 & 35.9 & 48.9 & 74.5 \\
\hline CKD-EPI creatinine-cystatin & 59.9 & 40.2 & 51.7 & 79.4 \\
\hline$C$ equation & & & & \\
\hline
\end{tabular}

Notes: $* P<0.001$ compared with the CKD-EPI creatinine-cystatin C equation GFR; ${ }^{\dagger} P<0.0$ I compared with the CKD-EPI creatinine-cystatin C equation GFR; $¥ P<0.05$ compared with the CKD-EPI creatinine-cystatin C equation GFR.

Abbreviations: CKD-EPI, Chronic Kidney Disease Epidemiology Collaboration; GFR, glomerular filtration rate; IQR, interquartile range; MDRD, Modification of Diet in Renal Disease. 
Table 4 Optimal scores* by equation

\begin{tabular}{ll}
\hline Equation & Total scores \\
\hline Cockcroft-Gault equation & 1.0 \\
Re-expressed 4-variable MDRD equation & 2.0 \\
CKD-EPI creatinine equation & 1.0 \\
CKD-EPI creatinine-cystatin C equation & 6.0 \\
\hline
\end{tabular}

Note: *The equation which performed the best overall scored I, and in each GFR subgroup scored 0.5 .

Abbreviations: CKD-EPI, Chronic Kidney Disease Epidemiology Collaboration; GFR, glomerular filtration rate; MDRD, Modification of Diet in Renal Disease.

body mass index $\left(<20 \mathrm{~kg} / \mathrm{m}^{2}: 1 ; \geq 20 \mathrm{~kg} / \mathrm{m}^{2}\right.$ and $<25 \mathrm{~kg} / \mathrm{m}^{2}: 2$; $\geq 25 \mathrm{~kg} / \mathrm{m}^{2}$ and $\leq 30 \mathrm{~kg} / \mathrm{m}^{2}: 3 ;>30 \mathrm{~kg} / \mathrm{m}^{2}: 4$ ) as the independent variables for regression analysis. We found that both higher GFR category and diabetes were independent factors that negatively correlated with $30 \%$ accuracy of the CKDEPI creatinine-cystatin $C$ equation $(\beta=-0.184$ and -0.113 , $P<0.001$ and $P=0.02$, respectively).

\section{Discussion}

Recently, measurement of serum cystatin $\mathrm{C}$ has been advocated as a simple, reliable, and accurate marker of GFR. ${ }^{17}$ Cystatin $\mathrm{C}$ is a low molecular weight protein that is freely filtered across the glomerular barrier and almost completely reabsorbed and catabolized by tubular cells. ${ }^{17}$ A cystatin-Cbased equation has many advantages over a creatinine-based one in the assessment of renal function in the elderly, since the creatinine-based one can be affected by a reduced muscle mass and other confounding factors such as age, race, sex, diabetes, and day-to-day variables. However, there is still no explicit evidence for superiority in this population in clinical practice. ${ }^{18,19}$ Furthermore, a cystatin-C-based estimation of GFR also showed only limited improvement in contrast to a creatinine-based formula. ${ }^{18}$ In 2012, a new CKD-EPI creatinine-cystatin $\mathrm{C}$ equation was developed based on both serum cystatin $\mathrm{C}$ and creatinine. The combined equation performed better than equations based on either marker alone. ${ }^{5}$ However, the CKD-EPI creatinine-cystatin C equation has not been validated in the elderly. The current study was designed to evaluate its performance in GFR estimation for the elderly Chinese population.

In this study, we found that although the bias of the CKD-EPI creatinine-cystatin C equation was greater than the other creatinine-based equations, the precision was improved with the CKD-EPI creatinine-cystatin $\mathrm{C}$ equation, leading to slight improvement in accuracy and the optimal scores of performance as well. Both higher GFR category and diabetes were independent factors negatively correlated with the $30 \%$ accuracy of the CKD-EPI creatinine-cystatin $\mathrm{C}$ equation.
These results confirmed that the combination of novel filtration markers, such as cystatin $\mathrm{C}$ and serum creatinine, into the GFR estimating formula may be a key to improving accuracy.

There were some limitations to this study. First, subjects represented a specific elderly cohort in the People's Republic of China; further validations in other age or racial populations are needed. Second, the difference in the measurement of GFR introduced systemic bias. ${ }^{20}$ Third, GFR estimating equation may be influenced by the difference of mGFR distribution and the cause of disease in the development population. ${ }^{21}$

In summary, comparing the creatinine-based equations, the CKD-EPI creatinine-cystatin $\mathrm{C}$ equation is more suitable for the elderly Chinese population. However, the costeffectiveness of the CKD-EPI creatinine-cystatin C equation for clinical use should be considered.

\section{Acknowledgments}

This work was supported by the National Natural Science Foundation of China (grant number 81370866 and number 81070612), the China Postdoctoral Science Foundation (grant number 201104335), the Guangdong Science and Technology Plan (grant number 2011B031800084), the Fundamental Research Funds for the Central Universities (grant number 11ykpy38), and the National Project of Scientific and Technical Supporting Programs Funded by the Ministry of Science and Technology of China (grant number 2011BAI10B00). This work was also supported in part by the National Natural Science Foundation of China (grant numbers 91029742, 81170647, and 81370837 to Hui Huang).

\section{Disclosure}

The authors report no conflicts of interest in this work.

\section{References}

1. Carter JL, Stevens PE, Irving JE, Lamb EJ. Estimating glomerular filtration rate: comparison of the CKD-EPI and MDRD equations in a large UK cohort with particular emphasis on the effect of age. QJM. 2011;104(10):839-847.

2. Stevens LA, Coresh J, Greene T, Levey AS. Assessing kidney function - measured and estimated glomerular filtration rate. $N$ Engl $J$ Med. 2006;354(23):2473-2483.

3. Liu X, Cheng MH, Shi CG, et al. Variability of glomerular filtration rate estimation equations in elderly Chinese patients with chronic kidney disease. Clin Interv Aging. 2012;7:409-415.

4. Liu $\mathrm{X}, \mathrm{Xu} \mathrm{H}$, Zheng Z, et al. Estimating glomerular filtration rates in elderly Chinese patients with chronic kidney disease: performance of six modified formulae developed in Asian populations. Clin Interv Aging. 2013;8:899-904.

5. Inker LA, Schmid CH, Tighiouart $\mathrm{H}$, et al. Estimating glomerular filtration rate from serum creatinine and cystatin C. $N$ Engl J Med. 2012;367(1): 20-29.

6. Heikkinen JO, Kuikka JT, Ahonen AK, Rautio PJ. Quality of dynamic radionuclide renal imaging: multicentre evaluation using a functional renal phantom. Nucl Med Commun. 2001;22(9):987-995. 
7. Pei X, Yang W, Wang S, et al. Using mathematical algorithms to modify glomerular filtration rate estimation equations. PLoS One. 2013;8(3):e57852.

8. Liu X, Pei X, Li N, et al. Improved glomerular filtration rate estimation by an artificial neural network. PLoS One. 2013;8(3):e58242.

9. Ma YC, Zuo L, Zhang CL, Wang M, Wang RF, Wang HY. Comparison of ${ }^{99 \mathrm{~m}}$ Tc-DTPA renal dynamic imaging with modified MDRD equation for glomerular filtration rate estimation in Chinese patients in different stages of chronic kidney disease. Nephrol Dial Transplant. 2007;22(2):417-423.

10. OpenEpi: Open Source Epidemiologic Statistics for Public Health, Version 2.3 [webpage on the Internet]. Available from: http://www. OpenEpi.com. Accessed July 6, 2013.

11. Ma YC, Zuo L, Chen JH, et al. Modified glomerular filtration rate estimating equation for Chinese patients with chronic kidney disease. J Am Soc Nephrol. 2006;17(10):2937-2944.

12. Xie P, Huang JM, Liu XM, Wu WJ, Pan LP, Lin HY. (99m)Tc-DTPA renal dynamic imaging method may be unsuitable to be used as the reference method in investigating the validity of CDK-EPI equation for determining glomerular filtration rate. PLoS One. 2013;8(5):e62328.

13. Cockcroft DW, Gault MH. Prediction of creatinine clearance from serum creatinine. Nephron. 1976;16(1):31-41.

14. Levey AS, Coresh J, Greene T, et al; Chronic Kidney Disease Epidemiology Collaboration. Using standardized serum creatinine values in the modification of diet in renal disease study equation for estimating glomerular filtration rate. Ann Intern Med. 2006;145(4):247-254.
15. Levey AS, Stevens LA, Schmid CH, et al; CKD-EPI (Chronic Kidney Disease Epidemiology Collaboration). A new equation to estimate glomerular filtration rate. Ann Intern Med. 2009;150(9): 604-612.

16. Efron B, Tibshirani RJ. An Introduction to the Bootstrap. London: CRC Press; 1993.

17. Filler G, Bökenkamp A, Hofmann W, Le Bricon T, Martínez-Brú C, Grubb A. Cystatin C as a marker of GFR - history, indications, and future research. Clin Biochem. 2005;8(1):1-8.

18. Burkhardt H, Bojarsky G, Gretz N, Gladisch R. Creatinine clearance, Cockcroft-Gault formula and cystatin C: Estimators of true glomerular filtration rate in the elderly? Gerontology. 2002;48(3): $140-146$.

19. Van Den Noortgate NJ, Janssens WH, Delanghe JR, Afschrift MB, Lameire NH. Serum cystatin C concentration compared with other markers of glomerular filtration rate in the old old. J Am Geriatr Soc. 2002;50(7):1278-1282.

20. Kwong YT, Stevens LA, Selvin E, et al. Imprecision of urinary iothalamate clearance as a gold-standard measure of GFR decreases the diagnostic accuracy of kidney function estimating equations. $\mathrm{Am} \mathrm{J}$ Kidney Dis. 2010;56(1):39-49.

21. Ma YC, Zuo L, Su ZM, et al. Distribution of reference GFR in a development population: a critical factor for the establishment of a GFR estimation equation. Clin Nephrol. 2011;76(4):296-305.
Clinical Interventions in Aging

\section{Publish your work in this journal}

Clinical Interventions in Aging is an international, peer-reviewed journal focusing on evidence-based reports on the value or lack thereof of treatments intended to prevent or delay the onset of maladaptive correlates of aging in human beings. This journal is indexed on PubMed Central, MedLine, the American Chemical Society's 'Chemical Abstracts

\section{Dovepress}

Service' (CAS), Scopus and the Elsevier Bibliographic databases. The manuscript management system is completely online and includes a very quick and fair peer-review system, which is all easy to use. Visit http://www.dovepress.com/testimonials.php to read real quotes from published authors. 